\title{
REVISTA
}

$\square$
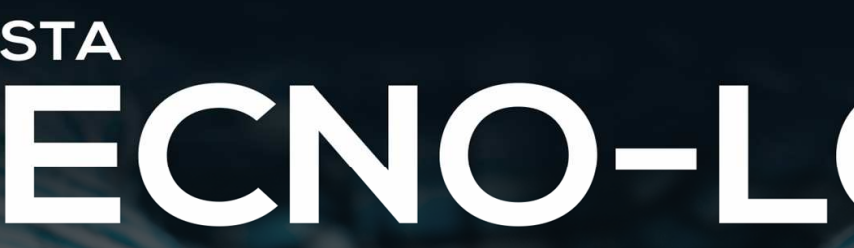

ISSN 1982-6753

Edição Especial com publicação de trabalhos selecionados do V SIGEPRO

\section{ANÁLISE DO NÍVEL DE ILUMINAMENTO EM UM INSTITUTO DE ENSINO FEDERAL, EM BELÉM-PA}

Leila de Fátima Oliveira de Jesus Robert ${ }^{1 *}$, José Maria Braga Pinto ${ }^{2}$, Bruno Lôbo de Almeida ${ }^{3}$, Jaime Felipe Costa Monteiro Tavares $^{3}$, Joelson Moreira Mendes $3^{3}$

1 Professor do Instituto Federal de Educação, Ciência e Tecnologia do Pará, CEP 66093-020, e da Universidade do Estado do Pará, CEP 66095-015, Belém, Pará, Brasil.

2 Professor do Instituto Federal de Educação, Ciência e Tecnologia do Pará, CEP 66093-020, Belém, Pará, Brasil.

3 Discentes do Instituto Federal de Educação, Ciência e Tecnologia do Pará, CEP 66093-020, e Bolsistas do projeto PIBIC-EM da Universidade do Estado do Pará, CEP 66095-015, Belém, Pará, Brasil.

*E-mail: professoraleilarobert@gmail.br

\section{RESUMO}

A ergonomia cognitiva está relacionada à percepção, atenção, memória e tomada de decisões. Para que o ser humano consiga ter bom desempenho cognitivo é muito importante que aspectos relacionados ao conforto ambiental sejam atendidos. A adequação do iluminamento no ambiente é fundamental para a produção, aprendizado e redução da fadiga visual. Ao mesmo tempo, em projetos elétricos é estabelecido que as cargas de iluminação devam ser determinadas como resultado da aplicação da NBR 5413: Iluminância de interiores - Procedimento. Assim sendo, essa pesquisa tem como objetivo analisar os níveis de iluminamento nos ambientes do Instituto Federal de Educação e Tecnologia do Pará (IFPA), campus Belém-PA. Para tanto, utilizou-se o método Lúmens, que se baseia na determinação do fluxo luminoso do ambiente. Onze ambientes foram analisados; estabeleceu-se o iluminamento médio do local; em função das dimensões do mesmo, usuários e da atividade; verificando o fluxo luminoso necessário para o atendimento da norma comparado ao fluxo luminoso existente no local. Como resultado, identificou-se que um ambiente apresenta fluxo luminoso acima do necessário, enquanto que $91 \%$ apresentaram abaixo, o que pode estar causando fadiga visual aos alunos e profissionais. Com efeito, não atendendo os parâmetros da ergonomia cognitiva que está ligada à percepção, atenção, memória e tomada de decisões. Confirma-se o fato de que mudanças nos ambientes devem ser acompanhadas por profissionais qualificados por haver consequentemente mudança no projeto elétrico inicial. Além disso, é importante que o projeto arquitetônico adote cores claras, que favoreçam o iluminamento artificial e que reduzam a potência da energia instalada.

Palavras-chave: Ergonomia cognitiva, Método lúmens; Conforto ambiental; Ambiente escolar, Nível de iluminamento. 
Edição Especial com publicação de trabalhos selecionados do V SIGEPRO

\section{Introdução}

De acordo com a Ergonomics Research Society, abordada na obra de Saliba [1], ergonomia é o estudo do relacionamento entre o homem e seu trabalho, equipamento e ambiente; a aplicação dos conhecimentos de anatomia, fisiologia e psicologia na solução dos problemas surgidos desse relacionamento. A ergonomia cognitiva tem como objeto de estudo os aspectos mentais, emocionais e psicomotores do profissional. Tais aspectos têm a ver com o processamento de informações no contexto de execução de tarefas. Sendo assim, está ligada à percepção, atenção, memória e tomada de decisões. Para que o ser humano consiga ter bom desempenho cognitivo é muito importante que aspectos relacionados ao conforto ambiental sejam atendidos, incluindo a adequação do iluminamento. Todos esses fatores são importantes para eficiência de produção e aprendizado.

A iluminação artificial tornou-se fundamental para vida humana, tem tido papel importante na economia desde a sua invenção. Adequar o nível de iluminação visando o conforto visual e bons desempenhos de produtividade e aprendizado tem se tornado um grande desafio. Segundo Loss [2] a luz controla inúmeros processos bioquímicos corporais além de impactar visivelmente todos os outros aspectos da existência humana, inclusive a arquitetura. Parâmetros relacionados ao iluminamento têm sido elementos importantes no projeto; este deve considerar combinação de cores, facilidade de manutenção, eficiência energética e boas condições de visibilidade. Um projeto luminotécnico tem a função de adequar a iluminação do ambiente para o que se destina. Proporcionar uniformidade da iluminação, evitando quantidade de luz excessiva e ofuscamento; além de, bem-estar, segurança e economia [3].

Dessa forma, na procura de condições que permitam o bem-estar das pessoas, tanto social como ocupacional, as condições adequadas de iluminamento devem ser priorizadas. Segundo Lima [4], 85\% da percepção humana é composta de informações visuais. A quantidade de luz é fundamental, uma vez que exerce influência no estado emocional e no bem-estar das pessoas.

Nessa perspectiva, o ambiente escolar, que concentra como base de atividade o processo de ensino-aprendizagem, tem como peculiaridade as habilidades de concentração e raciocínio. Sendo, portanto, amplamente influenciado por situações de conforto no local de trabalho. $\mathrm{O}$ ambiente escolar, onde os alunos passam boa parte do tempo, deve proporcionar condições favoráveis, sendo a iluminação uma das principais questões a serem analisadas. Autores efetuaram uma pesquisa sobre o impacto do design da sala de aula na aprendizagem dos alunos, no qual perceberam a importância de níveis adequados de iluminamento para o rendimento escolar, que pode influenciar diretamente no aprendizado [5].

Além do ensino-aprendizado, situações que acarretam danos à saúde, tanto para os alunos como para os profissionais que ali atuam, devem ser amenizadas. Os efeitos relacionados a fadiga visual, inicialmente temporários, no entanto, quando recorrentes, acarretam perturbações à saúde deixando os olhos vermelhos e lacrimejando, a visão turva, dificuldade de visão e dor de cabeça; principalmente, quando se frequenta por longos períodos um ambiente com iluminação inadequada [6].

Considerando também que o ambiente escolar tem grande importância no contexto socioeconômico de um país, tem sido em algumas instituições polo de assistência social contempladas por programas estudantis: alimentação, auxílios estudantis, tempo integral de estudo. Nessas condições o prédio escolar passa por muitas mudanças de layout e até de disposição de ambientes, sofrendo alterações antes não consideradas no projeto original. As mudanças de layout, de pintura das paredes e até do tipo de atividade a ser desenvolvida interferem nas condições iniciais nas 
Edição Especial com publicação de trabalhos selecionados do V SIGEPRO

quais o ambiente foi projetado e podem apresentar inadequações relacionadas ao conforto visual ao atual ambiente que se insere.

No projeto elétrico, os níveis adequados de iluminamento proporcionam o conforto visual. A NBR 5413 [7] - Iluminância de Interiores - define parâmetro de iluminação compatível, com o tipo de atividade realizada; para obtenção das condições da qualidade luminosa de um ambiente. No Brasil, apesar da NBR ISO 8995-1 (ABNT) [8] - Iluminação de ambientes de trabalho ser a norma atualizada em termos de projeto elétrico, nesta pesquisa será utilizada a NBR 5413 por ser a norma recomendada no item 17.5.3.3 da Norma Regulamentadora $\mathrm{n}^{\circ} 17$ - Ergonomia [9]. O propósito da ergonomia no que se refere ao ambiente de trabalho é atender ao bem-estar do operador, de modo que ele possa desenvolver as suas atividades desfrutando de conforto térmico, acústico e de iluminamento. As edificações construídas devem ter essa preocupação tanto em sua arquitetura quanto aos usuários.

A investigação de conforto ambiental em ambientes escolares deve ser uma ação constante, pautada na importância do aproveitamento ensino-aprendizagem e dos profissionais envolvidos com o aspecto técnico e administrativo. Muitas vezes a escola tem sido a extensão dos lares dos discentes, o que justifica o tema da pesquisa. França [10] aponta que os edifícios escolares possuem diversos ambientes e que as decisões tomadas para o projeto podem interferir diretamente no desempenho acadêmico dos alunos. Essas considerações podem ser estendidas para atividades de reformas e mudanças de layout.

Esta pesquisa visa efetuar um estudo do nível de iluminamento dos ambientes no IFPA, campus Belém, no bloco N. Dessa forma a pesquisa apresenta a seguinte problemática: o nível de iluminamento dos ambientes do IFPA, campus Belém, encontra-se adequado? Quais os níveis adequados e que medidas podem ser tomadas para manter a qualidade de iluminamento?
Portanto, a pesquisa possui como objetivo geral: analisar o nível de iluminamento do IFPA, campus Belém.

Como objetivos específicos:

1) avaliar dentro da legislação o iluminamento atual do instituto;

2) diagnosticar se os níveis de iluminamento estão adequados; e, por fim;

3) apresentar medidas ergonomicamente corretas para propiciar boa qualidade de iluminamento.

\section{Parte Experimental ou Metodologia}

A pesquisa foi efetuada nas dependências do Instituto Federal de Educação e Tecnologia do Pará (IFPA), campus Belém$\mathrm{PA}$, especificamente no bloco $\mathrm{N}$, que atende aos cursos técnicos de edificações, mineração e estrada; campus Belém. Fundamentou-se no estudo da implementação da iluminação artificial - Luminotécnica, baseado na norma NBR 5413 iluminância de interiores. O método utilizado na implementação desse estudo foi o Lumens [11].

\subsection{Etapas da pesquisa}

- Planejamento e produção dos layouts

A $1^{\text {a }}$ etapa do procedimento da pesquisa refere-se a de planejamento e layout: nesta fase foi efetuada a divisão de ambientes a serem analisados por período, acertado previamente com os servidores, de acordo com a disponibilidade local. (Fig.1)

Após o planejamento foram feitos os layouts das dependências e disposição das luminárias existentes. Utilizou-se o software Autocad para desenhar os ambientes e alocar as 
Edição Especial com publicação de trabalhos selecionados do V SIGEPRO

luminárias existentes. Além de efetuar as medições necessárias e anotações de cores de paredes, tetos e pisos. Também foi coletado a idade média das pessoas que mantinham atividades nos recintos e a precisão das tarefas. As coletas de dados foram realizadas em um instrumento que sintetizou as informações sobre o ambiente, os usuários, os tipos de luminárias e que possibilitou desenhar o croqui de cada ambiente.

Após a etapa inicial, os procedimentos de execução da pesquisa seguiram os passos, com base no método Lúmen.

Figura 1: Fluxo dos procedimentos metodológicos

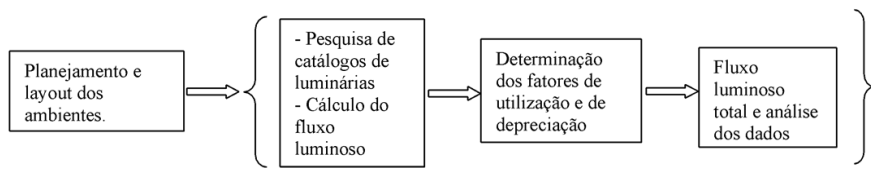

- Etapa com aplicação do método lumens

Para determinar o fluxo luminoso total, $1^{\circ}$ foi estabelecido do tipo de lâmpada e de luminária a serem utilizadas no local: identificou-se as lâmpadas existentes no local e utilizouse catálogos para escolha das luminárias.

A determinação do fluxo luminoso total deu-se pela expressão (1): $\emptyset=A \cdot E / \mu \cdot d$,

onde: $\emptyset$ : fluxo luminoso em lumens;

A: área da superfície iluminada $\left(\mathrm{m}^{2}\right)$;

E: nível de iluminância em lux;

$\mu$ : coeficiente de utilização;

d: fator de depreciação dos equipamentos.

- Verificou-se a Iluminância (E): considerou a partir da iluminação geral para área de trabalho, tarefas administrativas, de aprendizado e com uso de computador, com base na norma NBR 5413: Iluminância de interiores; iluminância em lux (500 - 750 - 1000). E para os fatores que determinam "o uso adequado de iluminância específica": idade, velocidade de precisão e refletância do fundo da tarefa. A refletância do fundo da tarefa e a idade foram definidas para cada ambiente. A velocidade de precisão foi considerada "importante" em todos os 11 ambientes, para auxilio dos cálculos utilizou-se uma apostila disponibilizada pela UNICAMP [12].

- A próxima etapa foi determinar o coeficiente de utilização $(\mu)$ : foi obtido a partir da luminária, considerando do índice do local (k), e os fatores de refletância da luz no teto, parede e piso, anotados (apêndice 1), quando realizados os croquis de cada um dos 11 ambientes. Em seguida, calculou-se o índice do local (k), expressão em que, $\mathrm{k}=\mathrm{C}$. L/ h. $(\mathrm{C}+\mathrm{L})$. Onde $\mathrm{C}$ é o comprimento do ambiente; $h$ altura do plano trabalho ao teto; e L é a largura do ambiente. Identificou-se nos catálogos das luminárias o índice de iluminação que correspondia à refletância e índice de local de cada ambiente. A interseção desses dados, concedeu o índice de iluminação.

- Para a determinação do fator de depreciação (d), foram consideradas as indicações dos fabricantes quanto a depreciação da luminária ao longo do tempo.

- Análise dos dados

Foram utilizados os croquis desenhados de cada ambiente, os cálculos sintetizados em quadros e planilhas através do software Excel para identificar as melhores opções de luminárias e de lâmpadas. A determinação do fluxo luminoso total (em lúmens) que as luminárias terão que produzir e do número de luminárias necessário para o ambiente. Foram analisadas as luminárias que pudessem gerar melhor eficiência energética, facilidade de manutenção e substituição de lâmpadas, para compor o ambiente. A partir do fluxo luminoso total necessário, determinou-se o número de lâmpadas necessárias, através da relação fluxo luminoso total $(\varnothing)$ pelo fluxo luminoso de cada lâmpada $(\varphi)$.

A matéria publicada nesse periódico é licenciada sob forma de uma Licença Creative Commons - Atribuiç̃o 4.0 Internacional http://creativecommons.org/licenses/by/4.0/ 


\section{Edição Especial com publicação de trabalhos selecionados do V SIGEPRO}

\section{Resultados e discussões}

A pesquisa limitou-se aos 11 ambientes estudados, os projetos foram reproduzidos em Autocad, adequando ao novo layout, com distribuição e as especificações das luminárias, entregues à instituição.

As luminárias escolhidas para substituir as existentes foram as dos tipos: Plafon, Ilumi 100W 250V (Fig. 2); Luminárias TBS027 - TLDRS Philips (Fig. 3); e luminária decorativa, modelo Safira, ITAIM (Fig. 4).

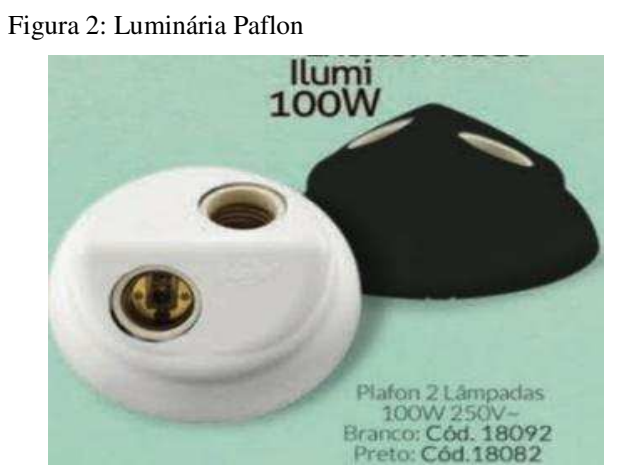

Figura 3: Luminárias TBS027 - TLDRS

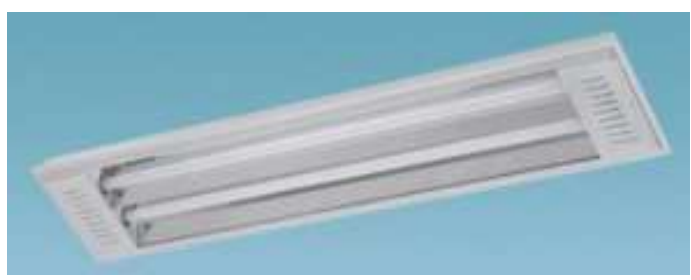

As informações sobre as dimensões, cores, idade média das pessoas e dados das luminárias existentes foram resumidas na tabela 1 a qual encontra-se disponível no Apêndice A.

Após a coleta de dados, foi calculado o fluxo total instalado. Como também a iluminância adequada, fator de manutenção e o fator de iluminação. O fluxo luminoso que incide sobre uma superfície situada a certa distância da fonte (iluminância em lux) foi estabelecido de acordo com a NBR 5413. Os que indicaram maior fluxo foram as coordenações, departamento de ensino recursos naturais e infraestrutura - DERIN e a sala de pesquisa 2 com 750 lux (Tabela 2 no Apêndice B). Para o fator de manutenção, estabeleceu-se 0,8 , considerando que há limpeza nas luminárias, conforme foi mencionado em pesquisa de campo. $\mathrm{O}$ fator de utilização, de forma intuitiva, mostra que parte do fluxo luminoso emitido pela lâmpada é absorvido pela luminária, parte reflete-se sobre as superfícies do recinto, até chegar ao plano de trabalho. E foi definido, de acordo com cada luminária, na maioria dos ambientes 1. Foi calculado o fluxo total instalado no ambiente e o fluxo total que é necessário, podendo então analisar quais ambientes necessitariam melhorar o iluminamento.

Verificou-se em campo que a distribuição das luminárias está uniformemente distribuída, atendendo ao critério da norma. No entanto, se for considerado a eficiência energética e o custo dessas instalações, percebeu-se que há um ambiente com fluxo instalado maior do que o necessário, corresponde à sala 02, mineração, o que pode ser prejudicial causando reflexos desnecessários. Tanto a iluminação insuficiente como as excessivas podem dificultar o desenvolvimento das atividades (ATLAS, 2019).

Os restantes dos ambientes apresentam fluxo inferior aos necessários: a exemplo a sala de desenho, que necessita ter um fluxo luminoso de 91.258,24 ( $\mathrm{lm})$ e tem apenas $44.640(\mathrm{~lm})$ instalada; e a sala de pesquisa 02 que necessita ter um fluxo luminoso de 33.385,13 (lm) e tem apenas $7.380(\mathrm{~lm})$ instalada. Os dois ambientes mencionados possuem a situação mais crítica porque foram os que apresentaram defasagem maior. A sala de desenho é onde os alunos desenvolvem projetos e muitas vezes permanecessem no ambiente fora do horário de aula para realizar 


\section{Edição Especial com publicação de trabalhos selecionados do V SIGEPRO}

as atividades de projeto designadas pelos professores. Segundo Prado Filho [13] locais com iluminação inadequada exigem um maior esforço visual dos indivíduos, podendo causar fadiga visual e diminuição da capacidade visual ao longo dos anos. Os outros ambientes possuem em média metade do fluxo total instalado abaixo do que é necessário. Dessa forma, apresenta-se uma sugestão de adequação das luminárias para o atendimento da norma (Tabela 3).

Tabela 3: Sugestão de adequação das luminárias considerando o fluxo luminoso necessário

\begin{tabular}{|c|c|c|}
\hline Ambiente & $\begin{array}{l}\text { Diferença } \\
\text { de fluxo } \\
\text { (lumens) }\end{array}$ & Sugestão apresentada \\
\hline $\begin{array}{c}\text { Antigo } \\
\text { laboratório }\end{array}$ & 18.240 & $\begin{array}{l}\text { Acrescentar mais } 5 \text { luminárias (2lamp) Em todas as } \\
\text { luminárias deve ter lâmpadas superled de } 12 \mathrm{w} \text {. }\end{array}$ \\
\hline Auditório II & 27.369 & $\begin{array}{l}\text { Acrescentar mais } 8 \text { luminárias (2lamp) Em todas as } \\
\text { luminárias deve ter lâmpadas superled de } 12 \mathrm{w} \text {. }\end{array}$ \\
\hline $\begin{array}{c}\text { Coord. } \\
\text { Estrada }\end{array}$ & 33.600 & $\begin{array}{l}\text { Acrescentar mais } 1 \text { luminária tubular (2lamp) Em } \\
\text { todas as luminárias deve ter lâmpadas led de } 40 \mathrm{w} \text {. }\end{array}$ \\
\hline $\begin{array}{l}\text { Coord. } \\
\text { Mineração }\end{array}$ & 25.200 & $\begin{array}{l}\text { Substituir as luminárias plafon por } \\
\text { tubulares(2lamp). Em todas as luminárias deve ter } \\
\text { lâmpadas led de } 40 \mathrm{w} \text {. }\end{array}$ \\
\hline $\begin{array}{c}\text { Derin } \\
\text { (recepção) }\end{array}$ & 12.000 & $\begin{array}{l}\text { Acrescentar mais } 1 \text { luminária (2lamp). Em todas as } \\
\text { luminárias deve ter lâmpadas superled de } 30 \mathrm{w} \text {. }\end{array}$ \\
\hline $\begin{array}{c}\text { Derin- } \\
\text { (escritórios) }\end{array}$ & 27.200 & $\begin{array}{l}\text { Acrescentar mais } 2 \text { luminárias (2lamp). Em todas } \\
\text { as luminárias deve ter lâmpadas superled de } 40 \mathrm{w} \text {. }\end{array}$ \\
\hline $\begin{array}{l}\text { Laboratório } \\
\text { Informática }\end{array}$ & 35.000 & $\begin{array}{l}\text { Em todas as luminárias deve ter lâmpadas superled } \\
\text { de } 25 \mathrm{w} \text {. }\end{array}$ \\
\hline $\begin{array}{c}\text { Sala } \\
\text { 2(mineração) }\end{array}$ & 15.000 & $\begin{array}{l}\text { Em todas as luminárias deve ter lâmpadas superled } \\
\text { de } 25 \mathrm{w} \text {. }\end{array}$ \\
\hline $\begin{array}{c}\text { Sala } \\
\text { 3(mineração) }\end{array}$ & 20.400 & $\begin{array}{l}\text { Em todas as luminárias deve ter lâmpadas superled } \\
\text { de } 40 \mathrm{w} \text {. }\end{array}$ \\
\hline $\begin{array}{l}\text { Sala de } \\
\text { desenho }\end{array}$ & 96.000 & $\begin{array}{l}\text { Em todas as luminárias deve ter lâmpadas superled } \\
\text { de } 30 \mathrm{w} \text {. }\end{array}$ \\
\hline $\begin{array}{c}\text { Sala de } \\
\text { pesquisa } 2\end{array}$ & 40.800 & $\begin{array}{l}\text { Acrescentar mais } 4 \text { luminárias (2lamp). Em todas } \\
\text { as luminárias deve ter lâmpadas superled de } 40 \mathrm{w} \text {. }\end{array}$ \\
\hline $\begin{array}{l}\text { genda: Fluxo } \\
\mathrm{w}(\text { super })=2.000 \\
\text { oular } 40 \mathrm{w}=4.000\end{array}$ & $\begin{array}{l}\text { de lâ } \\
25 \mathrm{w}(\mathrm{s}\end{array}$ & $\begin{array}{l}\text { das }(\text { led }): \quad 9 \mathrm{w}=800 ; \quad 12 \mathrm{w}=1.140 ; \quad 20 \mathrm{w}=1.800 \\
)=2.500 ; 30 \mathrm{w}(\text { super })=3.000 ; \quad 40 \mathrm{w}(\text { super })=3.400\end{array}$ \\
\hline
\end{tabular}

A sugestão apresentada (Tabela 3) leva em consideração a permanência da locação das luminárias já instaladas e a facilidade de manutenção, a fim de reduzir os custos. Para melhor eficiência energética, sugere-se, também, que seja efetuado o balanceamento das fases no quadro de distribuição e a verificação dos disjuntores para cada fase, quando efetuar a substituições das luminárias, pois pode haver sobrecarrega de alguma fase.

Além disso, um ambiente com iluminação inadequada não proporciona concentração e bem-estar para avanços no aprendizado e nas atividades técnico-administrativas efetuadas na instituição. O projeto elétrico inicial e as mudanças ocorridas ao longo dos anos no ambiente escolar; reforçam a hipótese de que as modificações devem ser acompanhadas por profissional que possa redefinir as luminárias para o ambiente. Muitas modificações foram realizadas no bloco estudado, uma vez que o instituto tem muitas obras e a coordenação de mineração está alocada no mesmo bloco de edificações. $\mathrm{O}$ que pode representar um indicador de que o projeto inicial não contemplava aquele remanejamento. Ainda sobre o projeto; as cores da parede, teto e piso; as tarefas realizadas no ambiente e a idade dos que utilizam interferem no cálculo do fluxo luminoso necessário. Então, mudar de ambiente às vezes significa ser remanejado para um local que as luminárias não foram projetadas para aquela função. Autores realizaram uma pesquisa sobre a sustentabilidade e otimização do conforto ambiental no ambiente escolar [14]. A pesquisa teve como objetivo revisar praticas arquitetônicas sustentáveis que possibilitem otimizar as condições de conforto visual, térmico e acústico no espaço escolar. Foram destacados vários itens que um espaço escolar precisa ter para que possa ser adequado. Tornam a edificação um local melhor, assim como são apresentadas opções sustentáveis a serem instauradas nesses ambientes. Percebeu-se que a utilização de estratégias adequadas na concepção do projeto arquitetônico ou reestruturação de espaços construídos, bem como recorrer a materiais alternativos, melhoram o conforto ambiental de salas de aula. Só que essa preocupação com o projeto arquitetônico, com o projeto elétrico só vai funcionar se as modificações respeitarem as cores usadas nos ambientes e as redefinições adequadas das luminárias. São ações importantes para 
Edição Especial com publicação de trabalhos selecionados do V SIGEPRO

proporcionar o conforto no que se refere ao iluminamento proporcionando melhorias cognitivas no que tange ao resultado ensino-aprendizagem. Percebe-se que a ergonomia ambiental, para que tenha seus parâmetros alinhados, requer ações continuadas tanto na concepção do projeto como suas modificações que ocorrem ao longo dos anos, com mudanças de gestões para sincronizar as ações pautadas na ergonomia cognitiva.

Como proposta para estudos futuros, sugere-se a implementação de um estudo nos ambientes dos outros blocos do instituto e em outros Campus, para formalizar uma análise completa sobre o nível de iluminamento da instituição, além de avançar para outras instituições de ensino.

\section{Conclusões}

A pesquisa alcançou os objetivos propostos, através da avaliação do fluxo luminoso existente nos ambientes e o necessário para o atendimento da norma. Verificou-se que um ambiente se encontrava com nível de iluminamento adequado, no entanto, muito aquém do necessário, permitindo um acréscimo de custo de energia. Enquanto que $91 \%$ dos ambientes apresentaram fluxo luminoso abaixo do necessário, em média, apenas metade do fluxo necessário. Tendo como situações críticas a sala de desenho e a sala de pesquisa 2 , a última precisa $4 \mathrm{x}$ mais do fluxo luminoso do que há instalado no local; o que pode estar causando fadiga visual aos profissionais e interferência no processo ensinoaprendizagem. Foi possível elaborar novos projetos adequando distribuição e as especificações das luminárias e lâmpadas e contribuir com melhoria do local. Confirma-se o fato de que mudanças nos ambientes devem ser acompanhadas por profissionais qualificados por haver consequentemente mudança no projeto elétrico inicial. Assim como as substituições das luminárias que devem ser feitas atendendo a mesma potência da que estava instalada. Além disso, é importante que o projeto arquitetônico adote cores claras, que favoreça o iluminamento artificial e que reduza a potência da energia instalada no local.

\section{Agradecimentos}

Agradecemos a parceria firmada entre a UEPA e o IFPA, através do projeto PIBIC-EM UEPA foi possível viabilizar bolsa de estudo para os discentes de ensino médio do IFPA. Esse artigo é a $1^{\mathrm{a}}$ parte da pesquisa integral, na qual foi possível a publicação de um $2^{\mathrm{a}}$ artigo avaliando o iluminamento dos ambientes da Universidade. Grata ao IFPA, grata à UEPA, à CAPES e aos bolsistas.

\section{ANALYSIS OF THE LIGHTING LEVEL IN A FEDERAL EDUCATION INSTITUTE, IN BELÉM-PA)}

ABSTRACT: Cognitive ergonomics is related to perception, attention, memory and decision making. For the human being to be able to have good cognitive performance, it is very important that aspects related to environmental comfort are met. The adequacy of lighting in the environment is essential for the production, learning and reduction of visual fatigue. At the same time, in electrical projects it is established that the lighting loads must be determined as a result of the application of NBR 5413: Interior illuminance - Procedure. Therefore, this research aims to analyze the lighting levels in the environments of the Federal Institute of Education and Technology of Pará (IFPA), campus Belém-PA. For this, the Lumens method was used, which is based on the determination of the luminous flux of the environment. Eleven environments were analyzed; the medium illumination of the place was established; according to its dimensions, users and 


\section{REVISTA}

$\square$
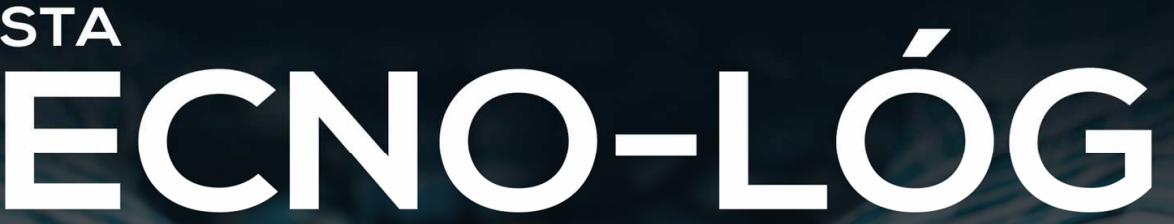

ISSN 1982-6753

Edição Especial com publicação de trabalhos selecionados do V SIGEPRO

activity; checking the luminous flux necessary to meet the standard compared to the luminous flux existing in the place. As a result, it was identified that an environment has a luminous flux above what is necessary, while $91 \%$ presented it below, which may be causing visual fatigue to students and professionals. Indeed, not meeting the parameters of cognitive ergonomics that is linked to perception, attention, memory and decision making. It confirms the fact that changes in environments must be accompanied by qualified professionals as there is consequently a change in the initial electrical project. In addition, it is important that the architectural design adopts light colors, that favor artificial lighting and that reduce the power of the installed energy.

Keywords: Cognitive ergonomics, Lumens method. Environmental comfort. School environment. lighting level.

\section{Referências}

[1] SALIBA, T. M. Curso básico de segurança e higiene ocupacional. 4.ed. São Paulo: LTR, 2011.

[2] LOSS, J. Iluminação Artificial Residencial: A percepção do usuário de Curitiba em ambientes de descanso. 2013. 99 p. Dissertação (Programa de Pós-Graduação em Engenharia de Construção Civil) - Setor de Tecnologia, Universidade Federal do Paraná, Curitiba, 2013.

[3] ROTH, C. L. The Hazars's of poor lighting in the workplace. Revista Européia Health \& Safaty international. Bilbau/ Espanha, 2012
[4] LIMA, M. R. C. Percepção Visual Aplicada a Arquitetura e Iluminação. Rio de Janeiro: Editora Ciência Moderna Ltda., 2010. 145 p.

[5] BARRETT, P. et al. The impact of classroom design on pupil's learning: Final results of a holistic, multi-level analysis. Building and Environment, [S.1], v. 89, 2015 .

[6] BERTOLOTTI, D. Iluminação natural em projetos de escolas: uma proposta de metodologia para melhorar a qualidade da iluminação e conservar energia. São Paulo, 2007.

[7] ASSOCIAÇÃO BRASILEIRA DE NORMAS TÉCNICAS. NBR 5413 Iluminância de Interiores. ABNT, Rio de Janeiro: 1992.

[8] NBR ISO/CIE 8995-1 - Iluminação de ambientes de trabalho. ABNT, Rio de Janeiro: 2013

[9] ATLAS. Segurança e medicina do trabalho: NR 17 - Ergonomia. 82a edição. Atlas, São Paulo: 2019.

[10] FRANÇA, A. J. G. L. Ambientes contemporâneos para o ensino-aprendizado: avaliação pós-ocupação aplicada a três edifícios escolares públicos, situados na região metropolitana de São Paulo. São Paulo - SP, 2011. Dissertação de mestrado. Universidade de São Paulo.

[11] LUZ, J. M. Luminotécnica. Porto Alegre; [sn], [20 (2017).

[12] UNICAMP. Laboratório de Iluminação UNICAMP: Tabelas de Iluminância e Cálculo luminotécnico. São Paulo: 2015. Disponível em: www.iar.unicamp.br/lab/luz/ld/Arquitetural/tabelas/luminotec-nica.pdf. Acesso em 07/11/2019.

[13] PRADO F. H. R. A iluminação pública deve obrigatoriamente obedecer a norma técnica. Revista Adnormas. São Paulo:2018.

[14] BURGOS et al. Otimização do conforto ambiental no espaço escolar: uma visão sustentável. Cinergis, 01 july 2015 Vol 16(1). 


\section{REVISTA}

Edição Especial com publicação de trabalhos selecionados do V SIGEPRO

\section{APÊNDICE A.}

Tabela 1: Dados por ambiente do instituto, campus Belém

\begin{tabular}{|c|c|c|c|c|c|c|c|c|}
\hline \multirow{3}{*}{ Ambiente } & \multicolumn{3}{|c|}{ Dimensões } & \multirow[b]{2}{*}{ Área do ambiente } & \multicolumn{4}{|c|}{ Luminária existente } \\
\hline & Comp. & Larg. & $\begin{array}{l}\text { Alt. d } \\
\text { mon } \\
\text { tagem }\end{array}$ & & $\begin{array}{l}\mathbf{I} \\
\mathbf{P} \\
\mathbf{0}\end{array}$ & $\begin{array}{l}\text { Quant. } \\
\text { Lumin. }\end{array}$ & $\begin{array}{c}\text { potência } \\
\text { lâmpadas }\end{array}$ & $\begin{array}{l}\text { Quant. } \\
\text { Lamp }\end{array}$ \\
\hline & (m) & (m) & (m) & $\left(\mathbf{m}^{2}\right)$ & & & $\mathbf{W}$ & \\
\hline Antigo laboratório & 2,34 & 4,27 & 1,95 & 9,99 & 2 & 1 & 18 & 2 \\
\hline Auditório II & 4,14 & 3,14 & 2,45 & 13,00 & 3 & 2 & 25 & 4 \\
\hline Coord. Estrada & 4,27 & 2,91 & 1,95 & 12,43 & 1 & 1 & 40 & 1 \\
\hline Coord. Mineração & 6,02 & 5,58 & 2,37 & 33,59 & 1 & 2 & 9 e 25 & 2 e 2 \\
\hline Derin (recepção) & 4,45 & 3,89 & 2,3 & 17,31 & 3 & 2 & 9 e 25 & 2 e 2 \\
\hline Derin-(escritórios) & 11,8 & 11,25 & 2,53 & 132,75 & 3 & 35 & 25 & 70 \\
\hline \multicolumn{9}{|l|}{ Laboratório } \\
\hline Informática & 11,39 & 2,94 & 2,45 & 33,49 & 3 & 6 & 20,23 e 25 & $2 ; 5$ e 4 \\
\hline Sala 02 (mineração) & 3,88 & 3,08 & 2,45 & 11,95 & 3 & 1 & 9 & $1 / 2$ \\
\hline Sala 03 (mineração) & 6,43 & 3,11 & 1,95 & 20,00 & 3 & 3 & 25 & 3 \\
\hline Sala de desenho & 8 & 6 & 2 & 48,00 & 1 & 6 & 30 & 6 \\
\hline Sala de pesquisa 2 & 2,92 & 3,01 & 2,66 & 8,79 & 3 & 2 & 20 & 4 \\
\hline
\end{tabular}

Legenda: tipo de luminária 1: Luminárias Plafon (2 lâmpadas) Ilumi 100W 250V; 2: Luminárias TBS027 - TLDRS Philips, 3: Luminária decorativa Safira, ITAIM. Fluxo (lâmpadas): $9 \mathrm{w}=860 ; 18 \mathrm{w}=1.350 ; 20 \mathrm{w}=1.200 ; 23 \mathrm{w}=1.426 ; 25 \mathrm{w}=1.600$; 


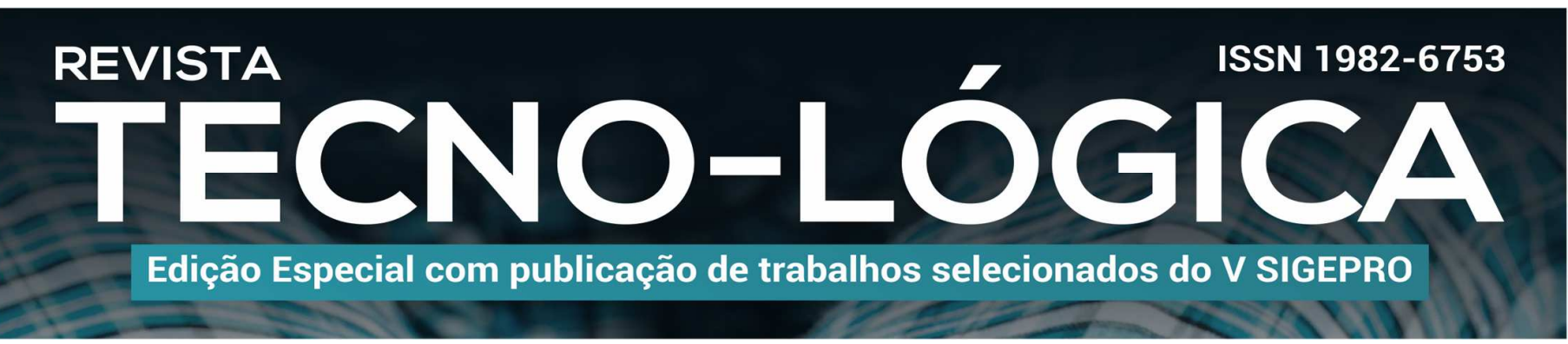

\section{APÊNDICE B}

(Tabela 2- Fluxo total instalado x fluxo total necessário).

$\begin{array}{cccc}\text { Fluxo total } & \text { Iluminância } & \mathbf{R C R}= & \mathbf{K}= \\ \text { instalado do } & \text { adequa } & \mathbf{5} * \mathbf{h} * & \mathbf{C} * \mathbf{L} / \\ \text { ambiente }-\varphi & \text { da para local } & ((\mathbf{C}+\mathbf{L}) / & (\mathbf{C}+\mathbf{L}) * \mathbf{H} \\ & \mathbf{E}=\varphi / \mathbf{S} & (\mathbf{C} * \mathbf{L}) & \end{array}$

Ambiente

Fator de manutenção FM $\begin{gathered}\text { Fator de utilização } \\ \text { FU }\end{gathered}$

Fluxo calculado necessário $\varphi=(\mathbf{E} * \mathbf{S}) /$ (FM* FU)

Resultado

\begin{tabular}{ccccc} 
& (lm) & (lux) & & \\
\hline Antigo laboratório & 8.370 & 300 & 3,155 & - \\
\hline Auditório II & 9.180 & 300 & 2,396 & 0,9229 \\
\hline Coord. Estrada & 15.000 & 750 & - & - \\
\hline Coord. Mineração & 9.126 & 750 & 3,099 & 0,7561 \\
\hline Derin (recepção) & 5.580 & 750 & - & 1,1845 \\
\hline Derin-(escritórios) & 11.160 & 750 & - & 1,3609 \\
\hline Laboratório Informática & 19.530 & 500 & - & 1,5618 \\
\hline Sala 02 (mineração) & 16.740 & 300 & - & 1,9928 \\
\hline Sala 03 (mineração) & 16.740 & 300 & 1,548 & - \\
\hline Sala de desenho & 44.640 & 500 & 3,242 & - \\
\hline Sala de pesquisa 2 & 7.380 & 750 & & \\
\hline
\end{tabular}

\begin{tabular}{cccc}
\hline & & (lumens) & \\
\hline 0,8 & 1 & $16.925,63$ & A melhorar \\
\hline 0,8 & 1 & $26.083,20$ & A melhorar \\
\hline 0,8 & 0,58 & $31.734,38$ & A melhorar \\
\hline 0,8 & 1 & $24.499,13$ & A melhorar \\
\hline 0,8 & 1 & $10.134,94$ & A melhorar \\
\hline 0,8 & 1 & $24.734,53$ & A melhorar \\
\hline 0,8 & 0,8 & $34.042,34$ & A melhorar \\
\hline 0,8 & 1 & $11.647,88$ & A melhorar \\
\hline 0,8 & 1 & $18.453,38$ & A melhorar \\
\hline 0,8 & 0,91 & $91.258,24$ & A melhorar \\
\hline 0,8 & 1 & $33.385,13$ & A melhorar \\
\hline
\end{tabular}

